\title{
Density structures inside the plasmasphere: Cluster observations
}

\author{
F. Darrouzet ${ }^{1}$, P. M. E. Décréau ${ }^{2}$, J. De Keyser ${ }^{1}$, A. Masson $^{3}$, D. L. Gallagher ${ }^{4}$, O. Santolik ${ }^{5, *}$, B. R. Sandel ${ }^{6}$, \\ J. G. Trotignon ${ }^{2}$, J. L. Rauch ${ }^{2}$, E. Le Guirriec ${ }^{2}$, P. Canu ${ }^{7}$, F. Sedgemore ${ }^{8}$, M. André ${ }^{9}$, and J. F. Lemaire ${ }^{1}$ \\ ${ }^{1}$ Belgian Institute for Space Aeronomy (IASB-BIRA), 1180 Brussels, Belgium \\ ${ }^{2}$ Laboratoire de Physique et Chimie de l'Environnement (LPCE/CNRS), Université d'Orléans, 45071 Orléans, France \\ ${ }^{3}$ Research and Scientific Support Department (RSSD), ESTEC-ESA, 2201-AG Noordwijk, The Netherlands \\ ${ }^{4}$ Marshall Space Flight Center (MSFC), NASA, Huntsville, AL 35805, USA \\ ${ }^{5}$ Faculty of Mathematics and Physics (MFF), Charles University, 12116 Prague, Czech Republic \\ ${ }^{6}$ Lunar and Planetary Laboratory (LPL), University of Arizona, Tucson, AZ 85721, USA \\ ${ }^{7}$ Centre d'étude des Environnements Terrestre et Planétaires (CETP/CNRS), Université de Versailles \\ Saint-Quentin-en-Yvelines, 78140 Vélizy, France \\ ${ }^{8}$ Formerly at Danish Space Research Institute (DSRI), 2100 Copenhagen, Denmark \\ ${ }^{9}$ Swedish Institute of Space Physics (IRFU), Uppsala division, 75121 Uppsala, Sweden \\ *also at Institute of Atmospheric Physics (IAP/CAS), 14131 Prague, Czech Republic
}

Received: 1 October 2003 - Revised: 11 May 2004 - Accepted: 18 May 2004 - Published: 14 July 2004

Part of Special Issue "Spatio-temporal analysis and multipoint measurements in space"

\begin{abstract}
The electron density profiles derived from the EFW and WHISPER instruments on board the four Cluster spacecraft reveal density structures inside the plasmasphere and at its outer boundary, the plasmapause. We have conducted a statistical study to characterize these density structures. We focus on the plasmasphere crossing on 11April 2002, during which Cluster observed several density irregularities inside the plasmasphere, as well as a plasmaspheric plume. We derive the density gradient vectors from simultaneous density measurements by the four spacecraft. We also determine the normal velocity of the boundaries of the plume and of the irregularities from the time delays between those boundaries in the four individual density profiles, assuming they are planar. These new observations yield novel insights about the occurrence of density irregularities, their geometry and their dynamics. These in-situ measurements are compared with global images of the plasmasphere from the EUV imager on board the IMAGE satellite.
\end{abstract}

Key words. Magnetospheric physics (plasmasphere) Space plasma physics (general or miscellaneous)

\section{Introduction}

The plasmasphere is a toroidal region in the inner magnetosphere populated by cold (a few $\mathrm{eV}$ or less), dense $\left(10-10^{4}\right.$ particles $\left./ \mathrm{cm}^{3}\right)$ ion and electron populations of ionospheric origin. It has been investigated by satellites and ground-based instruments (Lemaire and Gringauz, 1998, and references therein). The outer boundary of the plasmas-

Correspondence to: F. Darrouzet

(fabien.darrouzet@oma.be) phere, the plasmapause, has been discovered independently from ground-based whistler wave observations (Carpenter, 1963) and from in situ satellite measurements (Gringauz, 1963). It is often characterized by a sharp decrease in the plasma density, from $100-1000$ particles $/ \mathrm{cm}^{3}$ down to a few particles $/ \mathrm{cm}^{3}$. This knee is formed at an equatorial distance ranging from 2 to 8 Earth radii, depending on the level of the geomagnetic activity.

The Cluster mission is the first multi-spacecraft mission that surveys the plasmasphere. This paper focuses on Cluster observations of density structures. Before the Cluster mission, large fluctuations in the electron number density had been observed by OGO 5 (Chappell et al., 1970a), by CRRES near the plasmapause (LeDocq et al., 1994), by magnetospheric plasma analyzers on board geosynchronous satellites (Moldwin et al., 1995), and by various other groundbased and spacecraft instruments (see review by Carpenter and Lemaire, 1997). Density structures had also been inferred from high-resolution magnetometer data obtained during the Earth swing-by of Cassini (Southwood et al., 2001) by interpreting the magnetic field strength variations as signatures of diamagnetic plasma elements produced by the interchange instability (Lemaire, 1975). More recently, smallscale plasmaspheric density structures have been reported by the Radio Plasma Imager (RPI) on board IMAGE (Carpenter et al., 2002), and in the dusk sector by WHISPER on board Cluster (Décréau et al., submitted, $2004{ }^{1}$ ). Large-scale density structures have also been observed in the past and called

\footnotetext{
${ }^{1}$ Décréau, P. M. E., Le Guirriec, E., Rauch, J. L., Trotignon, J. G., Canu, P., Darrouzet, F., Lemaire, J., Masson, A., Sedgemore, F., and André, M.: Plasmapause formation and density irregularities: Cluster observations in the dusk sector, Adv. Space Res., submitted, 2004.
} 


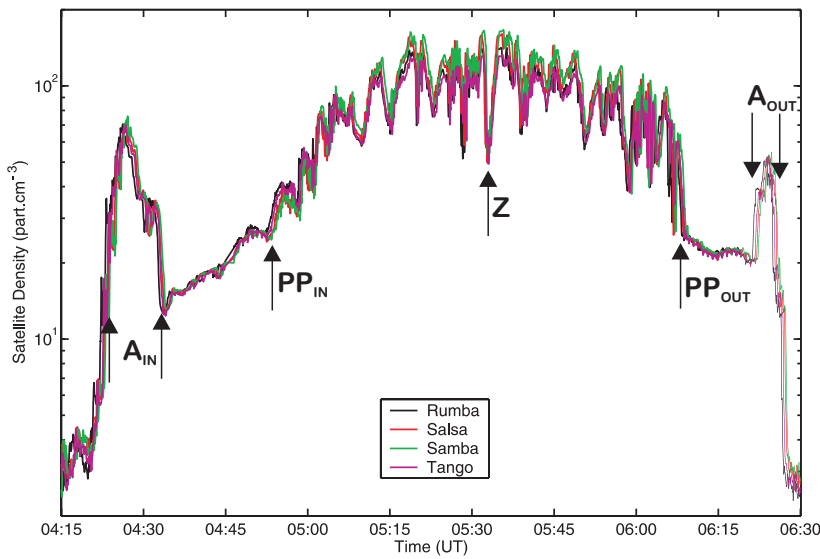

Fig. 1. Cluster electron density profiles derived from WHISPER and EFW as a function of time for the plasmasphere crossing on 11 April 2002, around 21:30 MLT and with $K_{p}=3$. A $\mathrm{A}_{I N}$ and $\mathrm{A}_{O U T}$ are the plasmaspheric plume crossings in the inbound and outbound passes, respectively, studied in Sect. 4.2, Z is the density irregularity discussed in Sect. 4.3, and $\mathrm{PP}_{I N}$ and $\mathrm{PP}_{O U T}$ are the plasmapause positions in the inbound and outbound crossings.

"detached plasma elements" or "plasmaspheric tails" (Chappell et al., 1970b; Horwitz et al., 1990). Recently, such structures, now called "plasmaspheric plumes", have been routinely observed by the global plasmaspheric imaging made by the Extreme Ultraviolet (EUV) imager on board IMAGE (Sandel et al., 2001; Goldstein et al., 2004). The formation of these plumes has been predicted by different theoretical models, based on a time dependent convection electric field (Grebowsky, 1970; Chen and Grebowsky, 1974), or based on the interchange instability mechanism (Lemaire, 2000; Pierrard and Lemaire, 2004).

The purpose of this paper is to report density structure observations by Cluster in the plasmasphere. After presenting the electron density data sets in Sect. 2, a statistical study of the occurrence of density irregularities as a function of magnetic local time (MLT) and geomagnetic activity will be discussed in Sect. 3. Section 4 focuses on the plasmasphere crossing on 11 April 2002, using WHISPER observations as well as other instruments on board Cluster. Coordinated observations from EUV complement the Cluster data for this event. Section 5 presents a summary and conclusions.

\section{Electron density data set}

The four Cluster spacecraft cross the plasmasphere near perigee (around $4 R_{E}$ ) every $57 \mathrm{~h}$ (Escoubet et al., 1997). These crossings go from the Southern to the Northern Hemisphere and uniformly cover all MLT sectors due to the yearly precession of Cluster. The electron density is obtained by combining data from two experiments: the Waves of HIgh frequency and Sounder for Probing Electron density by Relaxation, WHISPER (Décréau et al., 1997, 2001) and the Electric Field and Wave experiment, EFW (Gustafsson et al., 1997).
The WHISPER sounder unambiguously identifies the electron plasma frequency $\mathrm{F}_{p e}$ (the time resolution is $52 \mathrm{~s}$ in normal mode). $\mathrm{F}_{p e}$ is related to the electron density $\mathrm{N}_{e}$ by: $\mathrm{F}_{p e}\{\mathrm{kHz}\} \sim\left[81 \mathrm{~N}_{e}\left\{\mathrm{~cm}^{-3}\right\}\right]^{1 / 2}$ (Trotignon et al., 2001, 2003). $\mathrm{F}_{p e}$ can also be inferred from the WHISPER passive measurements by estimating the low frequency cut-off of natural emissions, which is equal to $\mathrm{F}_{p e}$ (the time resolution is $2.2 \mathrm{~s}$ in normal mode). EFW measures the potential difference $\mathrm{V}_{s c}$ between each antenna probe and the spacecraft (the spacecraft potential) every $0.2 \mathrm{~s}$. The $\mathrm{V}_{s c}-\mathrm{N}_{e}$ relationship is nonlinear and depends mainly on the electron plasma state (Pedersen, 1995; Laakso and Pedersen, 1998).

On a given Cluster perigee pass, the EFW measurements can be calibrated using the WHISPER observations, so as to infer $0.2 \mathrm{~s}$ electron density data (Pedersen et al., 2001). This calibration works well in the plasmasphere, but it is, however, only possible in regions where the frequency is below $80 \mathrm{kHz}$, i.e. the upper frequency limit of WHISPER. Above this instrumental threshold, $\mathrm{N}_{e}$ has been inferred from $\mathrm{V}_{s c}$ only, using a method presented by Moullard et al. (2002). Figure 1 depicts $\mathrm{N}_{e}$ as a function of time for the 11 April 2002 plasmasphere crossing; this particular event will be discussed in detail in Sect. 4.

In order to facilitate an intercomparison of the four Cluster density profiles, a combination of the internal magnetic field model IGRF95 and the external magnetic field model Tsyganenko-96 (Tsyganenko and Stern, 1996) is used to trace the magnetic field line from the spacecraft position to the geomagnetic equator. The IGRF95 and Tsyganenko96 models are computed with the Unilib library (Library of routines for magnetospheric applications: http://www.oma. be/NEEDLE/unilib.php/20x/index.html). The geomagnetic equator is identified as the location where the magnetic field strength reaches a minimum. The geocentric distance of this equatorial point is called $\mathrm{R}_{\text {equat }}$ and is expressed in units of Earth radii. We prefer to use $\mathrm{R}_{\text {equat }}$ instead of the McIlwain L parameter (Mcllwain, 1961), since it is easier to interpret: $\mathrm{L}$ varies along a magnetic field line, except for a pure dipole, whereas $\mathrm{R}_{\text {equat }}$ is by definition constant along a field line.

\section{Occurrence of density irregularities}

We have analyzed 33 plasmasphere crossings by the four satellites, i.e. a total of 264 inbound and outbound plasmapause crossings. We have used the $K_{p}$ index to evaluate the geomagnetic activity level, as in most previous studies of the plasmasphere. The plasmapause is assumed to be formed in the midnight sector following the theory that interchange motion is driven unstable along the Roche Limit surface (Lemaire, 1975, 2001). To try to compensate for the plasmasphere's rotation, a time delayed $K_{p}$ value is chosen that corresponds to the time elapsed since the observed structure passed the midnight meridian (assuming full corotation). The instantaneous value of $K_{p}$ is used when the spacecraft are between 21:00 and 03:00 MLT, the maximum value of $K_{p}$ in the preceding $6 \mathrm{~h}$ is used between 03:00 and 

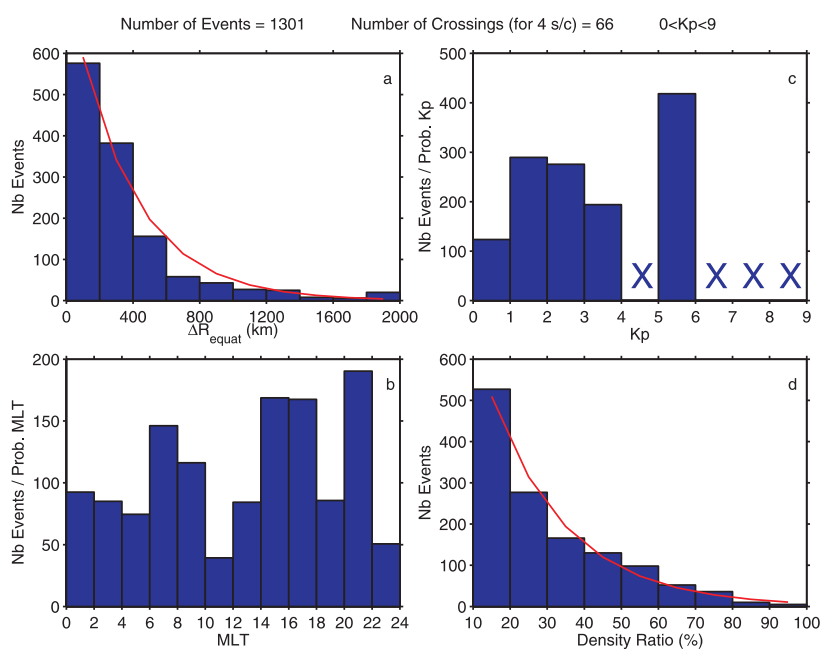

Fig. 2. Statistical results on the density irregularities observed during all 264 plasmasphere crossings: (a) the number of events as a function of the transverse equatorial size $\Delta \mathrm{R}_{\text {equat }}$ (in $\mathrm{km}$ ), (b) the MLT distribution divided by the probability to have a MLT in each range, (c) the $K_{p}$ distribution divided by the probability to have a $K_{p}$ in each range (a cross means no data), and (d) the density ratio. The red curves are exponential least-squares fitting curves.

09:00 MLT, the maximum value in the previous $12 \mathrm{~h}$ between 09:00 and 15:00 MLT, and the maximum value in the previous 18 $\mathrm{h}$ between 15:00 and 21:00 MLT. In the remainder of the paper, $K_{p}$ will denote this time delayed value.

Our sample contains only a few plasmasphere crossings for $K_{p} \geq 4$, in part because of the rather low probability for such a high level of activity. The fact that the Cluster spacecraft do not cross the plasmasphere for $K_{p} \geq 6$ confirms that in case of high geomagnetic activity, the plasmapause forms closer to the Earth, below the Cluster perigee, which is around $4 R_{E}$. In any case, the spacecraft remain in the outer plasmasphere.

Density irregularities have been defined by a density depletion ratio of at least 10\%. Panel (a) of Fig. 2 gives the occurrence of these irregularities as a function of their transverse equatorial size $\Delta \mathrm{R}_{\text {equat }}$ (in $\mathrm{km}$ ). Panels (b) and (c) show, respectively, the MLT and $K_{p}$ distribution of the irregularities weighted by the MLT and $K_{p}$ occurrence probability. Panel (d) gives the density ratio.

This survey suggests that there are more density irregularities in the dawn, afternoon and post-dusk sectors. It is interesting to note that two of these sectors correspond to the sectors where the plasmapause tends to be thicker. Irregularities rarely occur in the pre-noon and midnight sectors. Their transverse equatorial size and density depletion ratio distributions are exponential (following the red least-squares fitting curves on Fig. 2) with a characteristic size of $365 \mathrm{~km}$ and a characteristic density ratio of $20 \%$. The larger ones (in size) are observed when $K_{p}$ is small $\left(K_{p}<2\right)$. This is in part due to the fact that large ones cannot exist for high $K_{p}$ since the plasmasphere then is small. For $K_{p}$ below 2 (figure
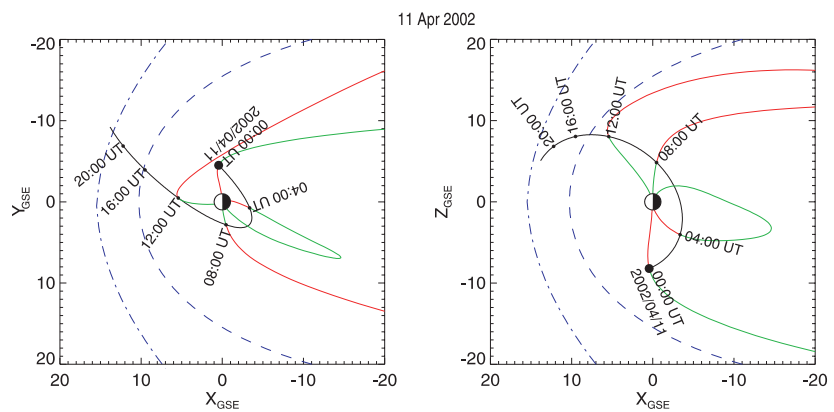

Fig. 3. Orbit of Cluster 3 in the XY and XZ GSE planes indicated by a solid black line, with tick marks every $4 \mathrm{~h}$. The dashed blue line indicates the position of the magnetopause and the bow shock is indicated by the dot-dashed blue line. When inside the magnetosphere, a magnetic field line has been traced from each tick mark location to the surface of the Earth or the magnetopause. Tracings parallel to the field (south-north) are shown in green and tracings anti-parallel (north-south) in red. (Courtesy of Cluster ground-based working group.)

not shown here), more density structures are observed in the dawn sector, while most of them are found in the dusk sector when $K_{p}$ is above 2. As expected, there are more density irregularities during and after periods of high geomagnetic activity, suggesting that they are generated near dusk by variations in the magnetospheric convection electric field. But as mentioned before, our sample has few cases with high $K_{p}$ and is therefore biased in this respect.

Irregular density profiles are predicted by plasmaspheric models that simulate the convection and refilling processes, like the CDPDM model (Galperin et al., 1997) and the selfconsistent RICE model (Spiro et al., 1981). Plasmaspheric refilling can produce density irregularities in the equatorial region (Singh, 1988; Singh and Horwitz, 1992). Turnings of the interplanetary magnetic field (IMF) influence the convection and might be responsible for the formation of density structures (Goldstein et al., 2002; Spasojević et al., 2003); IMF orientation might therefore be a useful alternative parameter to analyse the density irregularities distribution. Plasma interchange motion can also create density irregularities (Lemaire, 2001).

\section{Case study (11 April 2002)}

We have studied in more detail the plasmasphere crossing on 11 April 2002, between 21:40 and 21:10 MLT and with $K_{p}=3$. The spacecraft separation was small (around $150 \mathrm{~km}$ ). Figure 3 indicates the spacecraft orbits by a solid black line with tick marks every $4 \mathrm{~h}$. The mean position of the magnetopause and of the bow shock is indicated by dashed and dot-dashed blue lines, respectively. When inside the magnetosphere, a magnetic field line has been traced from each tick mark location to the surface of the Earth or to the magnetopause. 


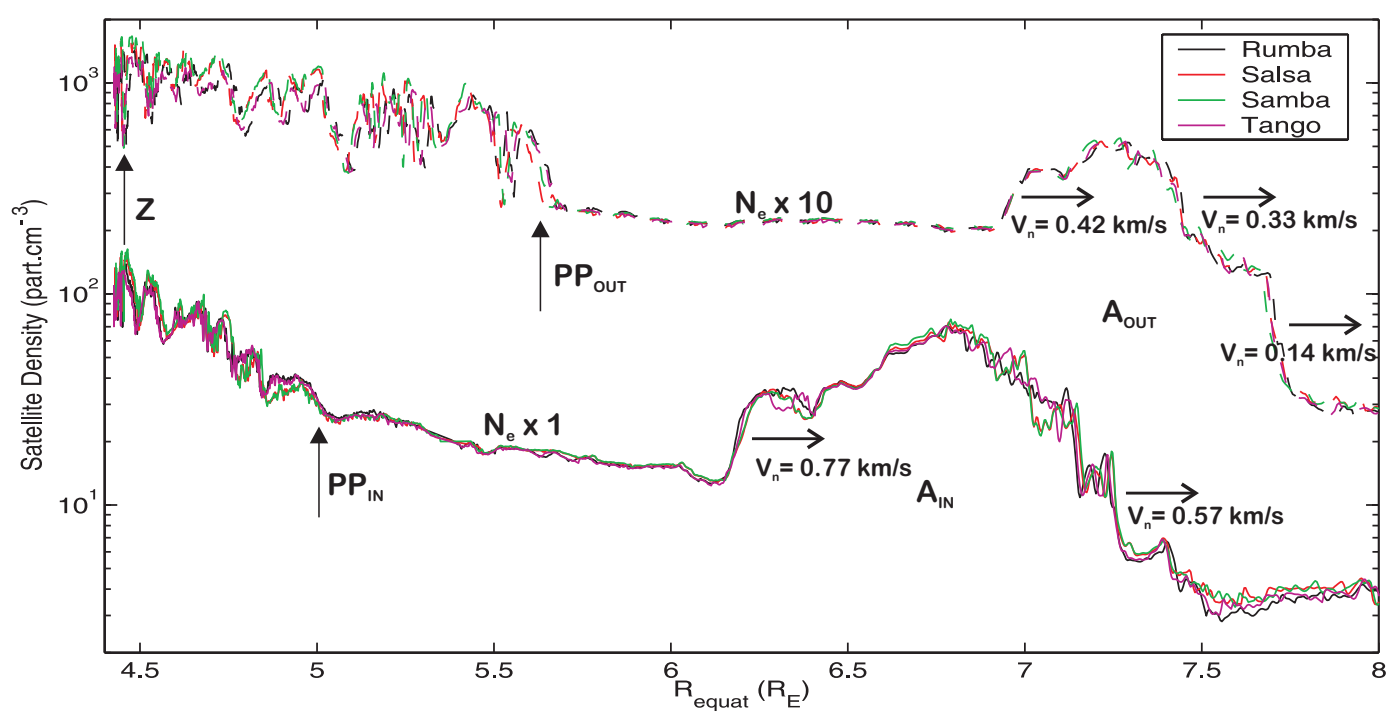

Fig. 4. Electron density profiles as a function of $\mathrm{R}_{\text {equat }}$ for the plasmasphere crossing on 11 April 2002. The lower four curves correspond to the inbound pass and the upper four curves (shifted by a factor 10) to the outbound pass. The normal boundary velocities $\mathrm{V}_{n}$ of the plume crossings $\mathrm{A}_{I N}$ and $\mathrm{A}_{O U T}$ are indicated on the figure.

Figure 4 plots the electron density profiles of Fig. 1 but as a function of $R_{\text {equat }}$ as defined in Sect. 2. The density profiles for the inbound pass are shown by the lower set of four curves and those for the outbound pass by the upper set of four curves (shifted by a factor 10). A plasmaspheric plume is seen in the inbound $\left(\mathrm{A}_{I N}\right)$ and outbound $\left(\mathrm{A}_{O U T}\right)$ passes. In the outbound pass the plume is narrower in $\mathrm{R}_{\text {equat }}$ scale and is observed at higher $\mathrm{R}_{\text {equat }}$. A lot of irregularities are visible in the plasmasphere. There are more density irregularities during the outbound pass (16) than during the inbound one (10). It is difficult to say if the four spacecraft cross the same density structures in both hemispheres during both passes, because we do not clearly recognize the same patterns on both sides of the equator, except for the plumes. There may be differences in the plasma density structures over small distances (hundreds of kilometres) and/or these structures may have changed over the time interval (tens of minutes) between both crossings.

\subsection{Analysis techniques}

To study plasmaspheric plumes and density irregularities with the Cluster constellation, we rely on two different fourpoint techniques described in Sects. 4.1.1 and 4.1.2. These are applied to the plasmaspheric plume traversals $\mathrm{A}_{I N}$ and $\mathrm{A}_{\text {OUT }}$ in Sect. 4.2 and to the density irregularities inside the plasmasphere in Sect. 4.3. In addition, we present in Sect. 4.1.3 how the EUV experiment on board the IMAGE spacecraft has been used to compare global images of the plasmasphere with in-situ Cluster results.

\subsubsection{Density gradient}

We compute the density gradient along the trajectory of the centre of mass of the Cluster tetrahedron. The method de- scribed by Harvey (1998) and Darrouzet et al. (2002) is used. The density gradient is determined from simultaneous measurements of the density, postulating that the four points of measurement are close enough to each other, so that all spacecraft are embedded in the same structure at the same time. The gradient can then be taken constant over the tetrahedron. The similarity of the four density profiles in Fig. 1 indicates that this assumption is approximately valid during this crossing: The density differences between the spacecraft come from small-scale irregularities, not large-scale.

The computation of a gradient is inherently a difficult operation: It involves differencing quantities of similar magnitude and thus results in large relative errors. To reduce such errors, we filter away, prior to computing the gradient, any variations at a time scale shorter than what we are interested in, by smoothing the density profiles with a time resolution of $20 \mathrm{~s}$ (100 km spatial resolution), which is the average time delay between the spacecraft. Furthermore, when the density is close to an extremum, the density gradient should be interpreted with caution.

\subsubsection{Velocities}

We distinguish in the following sections three different velocities: normal boundary velocity, azimuthal plasma velocity and radial boundary velocity.

We derive the velocity of a density structure boundary in the normal direction of the interface, $\mathrm{V}_{n}$, with a time delay method. Assuming a boundary to be a planar surface travelling at a constant velocity along its normal, we determine this velocity from individual spacecraft times and positions of the boundary crossings.

If the plasma is only co-rotating, i.e. moving in the azimuthal direction, the normal boundary velocity, $\mathrm{V}_{n}$, is the 

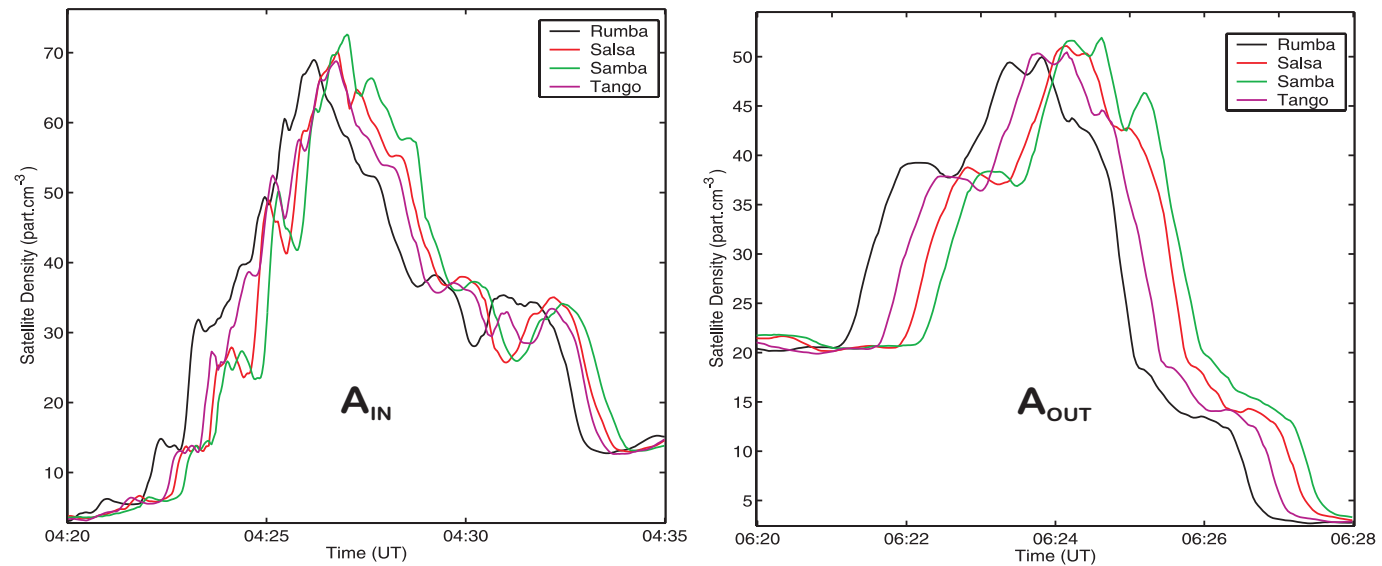

Fig. 5. Electron density profiles as a function of time of the two plume crossings $\mathrm{A}_{I N}$ and $\mathrm{A}_{O U T}$ observed on the inbound and outbound legs of the plasmasphere crossing on 11 April 2002.

projection of the azimuthal plasma velocity, $\mathrm{V}_{p}$, on the normal boundary direction: $\mathrm{V}_{n}=\mathrm{V}_{p} \sin \theta$, with $\theta$ the angle between the normal and the outward radial direction.

The radial boundary velocity, $\mathrm{V}_{r}$, which can be computed from the displacement of the boundary of a structure in the radial direction (at fixed MLT), is also related to the normal boundary velocity by: $\mathrm{V}_{n}=\mathrm{V}_{r} \cos \theta$.

\subsubsection{EUV images}

The Extreme Ultraviolet (EUV) imager on board the IMAGE spacecraft (Burch, 2000) provides global images of the plasmasphere with a spatial resolution of $0.1 R_{E}$ every $10 \mathrm{~min}$. The EUV instrument works by detecting $30.4 \mathrm{~nm}$ sunlight resonantly scattered by singly ionized helium (Sandel et al., 2000). Because of IMAGE high apogee $\left(\sim 7 R_{E}\right)$ and the EUV imager's wide field of view, images acquired at apogee show the structure of the entire plasmasphere. Sequences of such 2-D images show the shape of the plasmasphere, its evolution over time, and the motion of plasma irregularities at the plasmapause as well as inside the plasmasphere, illustrating the convection pattern.

The EUV images have been reprocessed to filter away the noise (apparent as high frequency spatial variations in the image) based on the fact that the larger scale density distribution in the plasmasphere (and a fortiori the emission intensities in the EUV images, which are line-of-sight integrations) is rather smooth. Histogram equalization and an appropriate color scale were used to improve the contrast in the images.

\subsection{Plasmaspheric plume}

The calculated normal boundary velocities $\mathrm{V}_{n}$ of the plasmaspheric plume crossings $\mathrm{A}_{I N}$ and $\mathrm{A}_{O U T}$ shown in Fig. 4 range between 0.14 to $0.77 \mathrm{~km} / \mathrm{s}$. The velocity of the spacecraft, $4.6 \mathrm{~km} / \mathrm{s}$, is significantly larger. The velocities along the inbound pass are larger at the inner edge of the structure than at the outer edge, and also larger than those mea- sured along the outbound pass. This is consistent with the assumption of an azimuthal motion of the plume, and with the topology of a plume getting thinner and extending farther out at earlier MLT (see Fig. 12 in Spasojević et al., 2003). Indeed the plume is crossed almost $2 \mathrm{~h}$ later in the outbound pass, and then it is observed to be thinner and at larger equatorial distance. The angle $\theta$ between the normal and the radial direction is between 20 and $70^{\circ}$. This implies an azimuthal plasma velocity $\mathrm{V}_{p}$ of the structures between 0.3 and $1 \mathrm{~km} / \mathrm{s}$. This is less than $30 \%$ of the co-rotation speed, which is $3.2 \mathrm{~km} / \mathrm{s}$ at the spacecraft radial distance. This indicates that these structures are not fully co-rotating, which is in agreement with results from the EDI instrument (Paschmann et al., 1997) on board Cluster in the same region (Matsui et al., 2003).

Since the Cluster orbit remains roughly at the same MLT during the whole crossing, we can estimate the radial boundary velocity $\mathrm{V}_{r}$ from the displacement between the inbound and outbound passes. The inner edge of this plume shifts $5100 \mathrm{~km}$ in $110 \mathrm{~min}$, which corresponds to $\mathrm{V}_{r}=0.77 \mathrm{~km} / \mathrm{s}$. $\theta$ is $40^{\circ}$ for this interface, which implies $\mathrm{V}_{n}=0.60 \mathrm{~km} / \mathrm{s}$. This speed is comparable to the $0.77 \mathrm{~km} / \mathrm{s}$ determined from the timing analysis in the inbound pass. For the outer edge, $\mathrm{V}_{r}$ is $0.42 \mathrm{~km} / \mathrm{s}, \theta$ is $50^{\circ}$, then $\mathrm{V}_{n}$ is $0.27 \mathrm{~km} / \mathrm{s}$, which has to be compared with $0.57 \mathrm{~km} / \mathrm{s}$.

The density gradient analysis cannot be applied here. The density profiles of both structures plotted as a function of time in Fig. 5 show that the four spacecraft successively cross the same structure, but they are never embedded in it at the same time because the boundaries are too narrow and/or because the spacecraft are not close enough. The density profiles of the plume $\mathrm{A}_{O U T}$ are very similar and are just shifted in time. This structure apparently does not change much on a time scale of $1 \mathrm{~min}$. The conservation of the crossing order by the four spacecraft confirms that this structure is moving progressively with respect to the spacecraft in the normal direction. While the density profiles for $\mathrm{A}_{I N}$ plotted as a function of time on Fig. 5 seem to differ somewhat between 


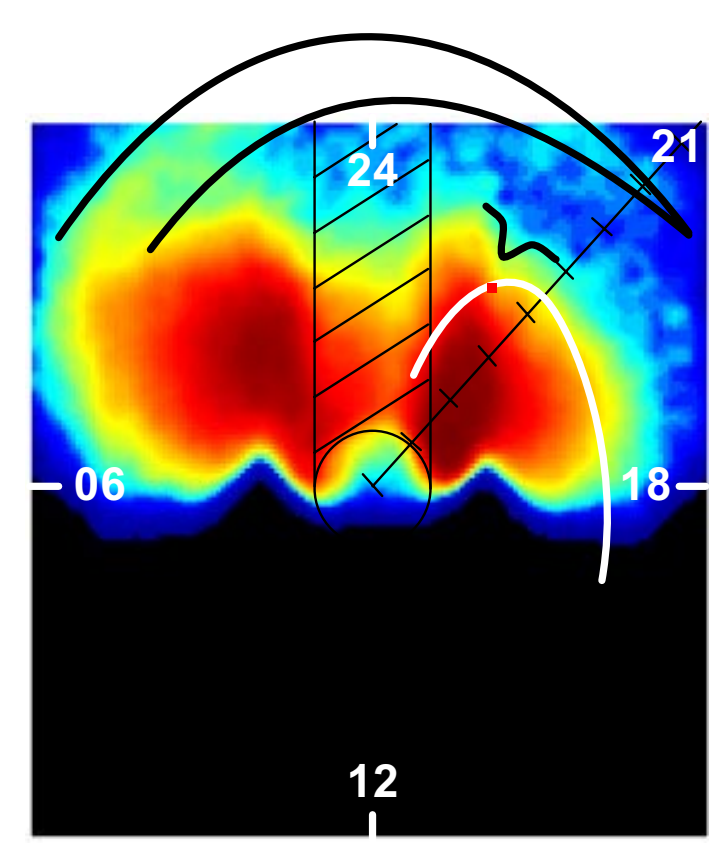

Fig. 6. EUV image at 04:32 UT on 11 April 2002. The image has been smoothed by a spatial low frequency filter. Contrast has been enhanced by means of a nonlinear color scaling based on histogram equalization. The black circle corresponds to the approximate size and position of the Earth, with its shadow extending towards the opposite direction to the Sun. The plume is delimited by the black line and one density irregularity is indicated by the small black indentation. The white curve is the trajectory of the four Cluster satellites between $3 \mathrm{~h}$ before and $3 \mathrm{~h}$ after the time of this EUV image, and the red dot corresponds to the position of the Cluster spacecraft at 04:32 UT.

the spacecraft, the density profiles as a function of $\mathrm{R}_{\text {equat }}$ in Fig. 4 are much more similar, showing the usefulness of the spatial equatorial view, which removes the time lag between the four spacecraft, and also the differences in latitude. The density gradient can be reliably calculated in the region between each plume crossing and the very perturbed plasmasphere proper. The values are very small, showing that the medium is very uniform there.

Figure 6 shows an EUV image of the plasmasphere at 04:32 UT on 11 April 2002 (around the timing of the inbound crossing of the plume by the Cluster satellites). IMAGE was then located high above the northern pole. The Sun is towards the bottom of this picture and the size and location of the Earth are indicated by the black circle, prolonged by the Earth's shadow extending through the plasmasphere in the opposite direction of the Sun. The plume is delimited by the wide black line. The black area in this image corresponds to a data gap. The white curve is the trajectory of the four Cluster satellites projected along a field line onto the equatorial plane. The red dot corresponds to the location of the Cluster spacecraft at 04:32 UT. It should be pointed out that image intensities scale with line-of-sight densities that are not necessarily projected onto the equatorial plane, but as the satellite is located at high altitude above the pole, the plane of

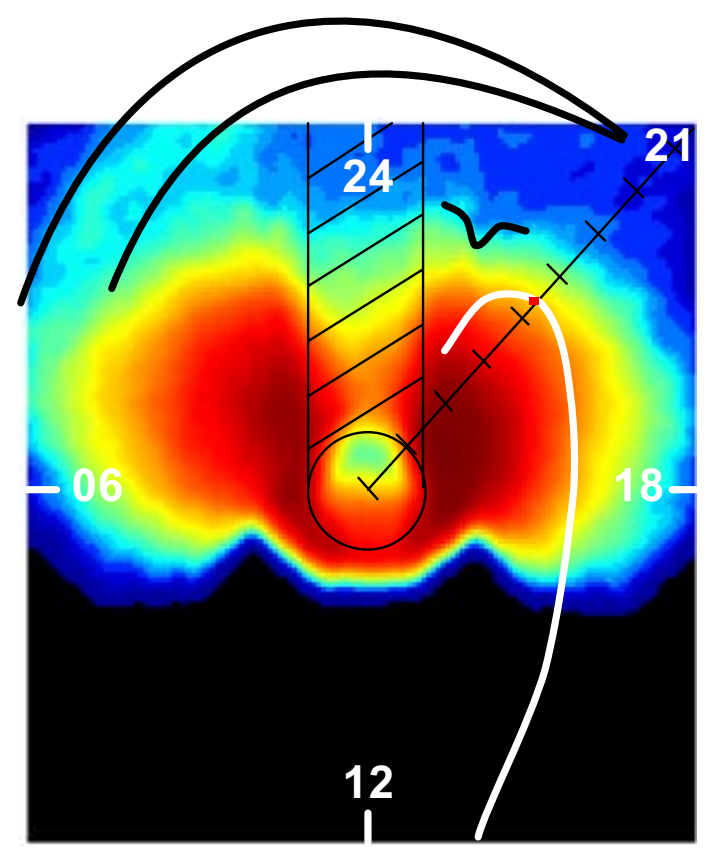

Fig. 7. EUV image at 06:04 UT on 11 April 2002 (same type as Fig. 6).

view of the EUV instrument is close to the equatorial plane. Therefore, the distances expressed in $\mathrm{R}_{\text {equat }}$ are only approximate.

At 21:40 MLT, the position of the plasmapause determined from the EUV picture (as the sharp boundary between the green and the blue part) is around $\mathrm{R}_{\text {equat }}=4.7 R_{E}$. This is close to the plasmapause detection at $5 R_{E}$ by Cluster at 04:55 UT. A plasmaspheric plume is clearly seen on this figure in the post-midnight sector (between 01:00 and 03:00 MLT), with the centre extending from $\mathrm{R}_{\text {equat }}=6.2 R_{E}$ (where the plume is attached to the plasmasphere) to $6.6 R_{E}$ (where it leaves the EUV field of view) and with a transverse size of about $1.4 R_{E}$. Less pronounced is a structure between 20:30 and 22:00 MLT, which might be the tail of the plume, whereas there is a gap in the observation of this supposed global plume on the EUV image. The centre of this structure extends from $\mathrm{R}_{\text {equat }}=6.7$ to $7 R_{E}$, and has a transverse size of about $0.7 R_{E}$. These EUV observations are consistent with the large plume structure seen by Cluster in the inbound crossing around 04:30 UT, at 21:40 MLT, between $\mathrm{R}_{\text {equat }}=6.2$ and $7.2 R_{E}$, and in the outbound crossing around 06:20 UT, at 21:10 MLT, between $\mathrm{R}_{\text {equat }}=6.9$ and $7.7 R_{E}$. The fact that this feature is not so clearly seen in the evening sector is due to its low density, close to the EUV threshold density of $40 \pm 10$ particles $/ \mathrm{cm}^{3}$, as estimated by Goldstein et al. (2003). This is consistent with the densities measured by Cluster. The density decrease from the inbound to the outbound pass ( $2 \mathrm{~h}$ later) is also consistent with being in the tail of the plume. Figure 7 is of the same type as Fig. 6, but at 06:04 UT. The plume is still present in the post-midnight sector, and it has rotated during the $90 \mathrm{~min}$ between the two pictures. 
The shape of the plume in the EUV images is consistent with the topology of the plume deduced from Cluster measurements in terms of position, size and intensity. It is surprising to observe such a long and long-lived structure in this low to moderate geomagnetic situation. Cluster and IMAGE provide complementary views of the plasmasphere, each with its own point of view and different time and space resolution.

\subsection{Density irregularities inside the plasmasphere}

As an example of density irregularities inside the plasmasphere, we focus on a small structure observed around 05:30 UT (indicated on Figs. 1 and 4 by the letter Z). Being close to the equator at that time, the trajectories of the four spacecraft are almost parallel to the magnetic field. The density gradient is parallel to the XY plane (Fig. 8) and nearly perpendicular to the magnetic field (its projections onto the plane of reference are shown by black arrows in this figure). This density gradient lies in the equatorial plane, as expected for a density structure close to the equator.

The normal boundary velocity of the inner interface of this plasma element, as determined from the time delay method, is $\mathrm{V}_{n}=1.90 \mathrm{~km} / \mathrm{s}$. Its projections onto the GSE planes (orange arrows on Fig. 8) show a large component in the X-direction. This density irregularity being observed well inside the plasmasphere, at $4.5 R_{E}$, the assumption of azimuthal motion is justified. The angle $\theta$ between the direction of the density gradient, which is the normal direction, and the radial direction, is $55^{\circ}$. The measured $\mathrm{V}_{n}$ then implies an azimuthal plasma velocity $\mathrm{V}_{p}=2.3 \mathrm{~km} / \mathrm{s}$, which is essentially the corotation speed at this equatorial distance $(2.1 \mathrm{~km} / \mathrm{s})$. The same result is obtained for the outer part of this density irregularity $(2.2 \mathrm{~km} / \mathrm{s})$. That confirms that this density element is indeed fully co-rotating. This is consistent with the EDI drift velocity statistical analysis (Matsui et al., 2003). These results are also in agreement with velocity measurements from the CIS experiment (Rème et al., 2001), in the RPA mode (ion energies from about 0 to $25 \mathrm{eV}$ ) that show a motion of the density irregularities inside the plasmasphere in the corotation direction (Dandouras, 2003, personal communication).

The order of crossing by the four spacecraft is the same in the inbound and in the outbound crossing, which means that the structure is simply rotating with the plasma around the Earth. Repeating the same analysis for several other density irregularities, we conclude that most of them move with an azimuthal velocity between 1.5 and $2 \mathrm{~km} / \mathrm{s}$ in a direction that has a small Z-component, which coincides more or less with the co-rotation velocity. It is interesting to note that the STAFF experiments on board Cluster (Cornilleau-Wehrlin et al., 2003) observe a good correlation of whistler-mode emissions with these density irregularities.

The density irregularities observed with WHISPER inside the plasmasphere are not clearly seen at the same time in the EUV image (on Figs. 6 and 7) because of the spatial resolution of the EUV instrument, which cannot resolve structures
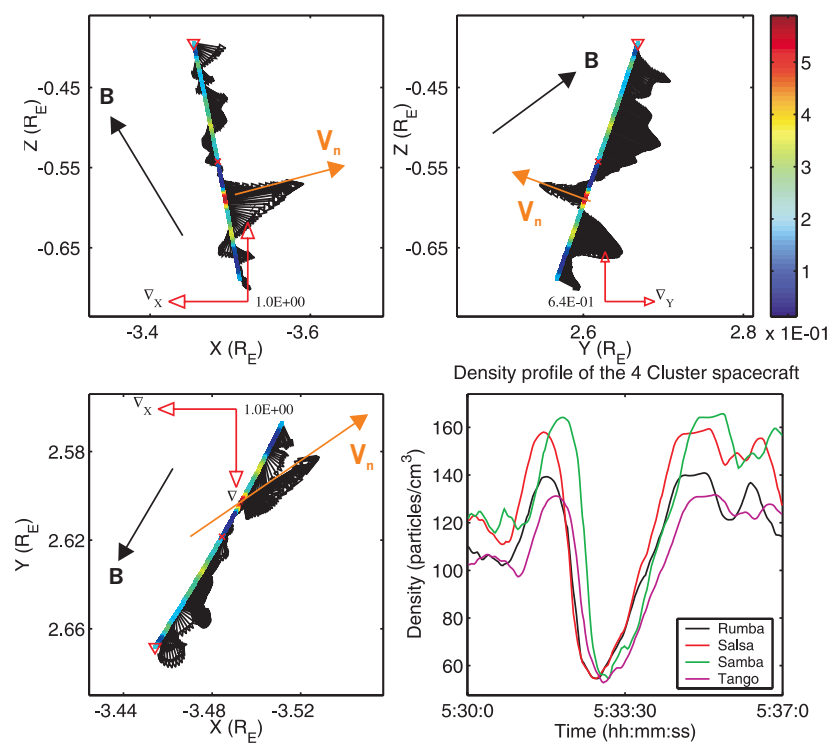

Fig. 8. Density gradient vector projections onto the XY, YZ, and $\mathrm{XZ} \mathrm{GSE} \mathrm{planes} \mathrm{for} \mathrm{the} \mathrm{density} \mathrm{irregularity} \mathrm{Z}$ observed in the plasmasphere on 11 April 2002. $\mathrm{B}$ is the magnetic field and $V_{n}$ is the normal boundary velocity of the inner edge of $Z$. The density of the four spacecraft is plotted as a function of time in the lower right panel.

with a size smaller than $0.1 R_{E}$, and because of the line-ofsight integration. The EUV images clearly show co-rotating plasmapause indentations (as indicated on Figs. 6 and 7), but it is difficult to ascertain the correspondence with structures observed by Cluster.

\section{Summary and conclusion}

Over 260 Cluster plasmasphere crossings have been examined in this first analysis. Density irregularities are often, though not always, seen in the plasmasphere and at the plasmapause. Their existence makes the identification of the actual plasmapause knee more difficult. The density irregularities have a transverse equatorial size that is exponentially distributed, with a characteristic value of $365 \mathrm{~km}$ going up to $5000 \mathrm{~km}$. They have a characteristic density ratio of $20 \%$. There are more density irregularities when the level of geomagnetic activity is higher. There seems to be an MLT asymmetry in their distribution. All these results show that the plasmasphere is a much more complex and dynamic region than considered so far from earlier experimental observations as well as from some early theoretical models and MHD simulations.

In a case study of the plasmasphere crossing on 11 April 2002, with small separation between the four Cluster spacecraft and with a good conjunction with the IMAGE spacecraft, a large plasmaspheric plume is observed outside the plasmasphere. This large-scale feature persists during a long period of time, but its width and position change between the inbound and the outbound passes. This evolution 
can be explained by the azimuthal motion of a plume that becames thinner and extends farther out at earlier MLT. This plasmaspheric plume topology is confirmed by EUV images.

This case study also revealed many density irregularities inside the plasmasphere, which are mostly co-rotating around the Earth. Co-rotating density structures are also seen by EUV on board IMAGE. These results are in agreement with observations from other instruments on board Cluster (CIS and EDI). The density gradients in these irregularities are perpendicular to the magnetic field in the equatorial region, showing that these irregularities are field aligned. We observe small-scale variability in the density profiles from Cluster, both spatially and temporally.

As expected, there are more density irregularities during and after periods of high geomagnetic activity, likely related to the mechanism of their formation. Once created, these structures are partially or fully co-rotating around the Earth. For the event studied, the IMF $\mathrm{B}_{z}$ turned southward and northward several times in the hours and day preceding the crossing. This could have been a trigger to form the density structures reported here.

A more complete statistical analysis is needed to confirm these preliminary conclusions. Indeed, a larger sample of plasmapause crossings is needed for this purpose. This analysis will be performed in the mid-term future over the full Cluster database.

Acknowledgements. F. Darrouzet, J. De Keyser, and J. F. Lemaire acknowledge the support by the Belgian Federal Science Policy Office through the CLUSTER/PRODEX-7 project (contract $\mathrm{n}^{\circ} 13127 / 98 / \mathrm{NL} / \mathrm{VJ}$ (IC)).

Topical Editor T. Pulkkinen thanks Y. Ebihara and another referee for their help in evaluating this paper.

\section{References}

Burch, J. L.: IMAGE mission overview, Space Sci. Rev., 91, 1-14, 2000.

Carpenter, D. L.: Whistler evidence of a "knee" in the magnetospheric ionization density profile, J. Geophys. Res., 68, 16751682, 1963.

Carpenter, D. L. and Lemaire, J.: Erosion and recovery of the plasmasphere in the plasmapause region, Space Sci. Rev., 80, 153179, 1997.

Carpenter, D. L., Spasojević, M. A., Bell, T. F., Inan, U. S., Reinisch, B. W., Galkin, I. A., Benson, R. F., Green, J. L., Fung, S. F., and Boardsen, S. A.: Small-scale fieldaligned plasmaspheric density structures inferred from the Radio Plasma Imager on IMAGE, J. Geophys. Res., 107, 1258, doi:10.1029/2001JA009199, 2002.

Chappell, C. R., Harris, K. K., and Sharp, G. W.: A study of the influence of magnetic activity on the location of the plasmapause as measured by OGO 5, J. Geophys. Res., 75, 50-56, 1970a.

Chappell, C. R., Harris, K. K., and Sharp, G. W.: The morphology of the bulge region of the plasmasphere, J. Geophys. Res., 75, 3848-3861, 1970b.

Chen, A. J. and Grebowsky, J. M.: Plasma tail interpretations of pronounced detached plasma regions measured by Ogo 5, J. Geophys. Res., 79, 3851-3855, 1974.
Cornilleau-Wehrlin, N., Chanteur, G., Perraut, S., Rezeau, L., Robert, P., Roux, A., de Villedary, C., Canu, P., Maksimovic, M., de Conchy, Y., Hubert, D., Lacombe, C., Lefeuvre, F., Parrot, M., Pincon, J. L., Décréau, P. M. E., Harvey, C. C., Louarn, Ph., Santolik, O., Alleyne, H., Roth, M., Chust, T., Le Contel, O., and STAFF team: First results obtained by the Cluster STAFF experiment, Ann. Geophys., 21, 437-456, 2003.

Darrouzet, F., Décréau, P. M. E., and Lemaire, J.: The Cluster Mission, Preliminary Results Obtained with the WHISPER Experiment, Physicalia Magazine, 24, 1-16, 2002.

Décréau, P. M. E., Fergeau, P., Krasnoselskikh, V., Lévêque, M., Martin, Ph., Randriamboarison, O., Sené, F. X., Trotignon, J. G., Canu, P., Mögensen, P. B., and Whisper investigators: Whisper, a resonance sounder and wave analyser: performances and perspectives for the Cluster mission, Space Sci. Rev., 79, 157-193, 1997.

Décréau, P. M. E., Fergeau, P., Krasnoselskikh, V., Le Guirriec, E., Lévêque, M., Martin, Ph., Randriamboarison, O., Rauch, J. L., Sené, F. X., Séran, H. C., Trotignon, J. G., Canu, P., Cornilleau, N., de Féraudy, H., Alleyne, H., Yearby, K., Mögensen, P. B., Gustafsson, G., André, M., Gurnett, D. A., Darrouzet, F., Lemaire, J., Harvey, C. C., Travnicek, P., and Whisper experimenters: Early results from the Whisper instrument on CLUSTER: an overview, Ann. Geophys., 19, 1241-1258, 2001.

Escoubet, C. P., Russell, C. T., and Schmidt, R.: The Cluster and Phoenix Missions, Kluwer Academic Publishers, 1997.

Galperin, Y. I., Soloviev, V. S., Torkar, K., Foster, J. C., and Veselov, M. V.: Predicting plasmaspheric radial density profiles, J. Geophys. Res., 102, 2079-2091, 1997.

Goldstein, J., Spiro, R. W., Reiff, P. H., Wolf, R. A., Sandel, B. R., Freeman, J. W., and Lambour, R. L.: IMF-driven overshielding electric field and the origin of the plasmaspheric shoulder of May 24, 2000, Geophys. Res. Lett., 29, (16), doi:10.1029/2001GL014534, 2002.

Goldstein, J., Spasojević, M., Reiff, P. H., Sandel, B. R., Forrester, W. T., Gallagher, D. L., and Reinisch, B. W.: Identifying the plasmapause in IMAGE EUV data using IMAGE RPI in situ steep density gradients, J. Geophys. Res., 108, 1147, doi:10.1029/2002JA009475, 2003.

Goldstein, J., Sandel, B. R., Thomsen, M. F., Spasojević, M., and Reiff, P. H.: Simultaneous remote sensing and in situ observations of plasmaspheric drainage plumes, J. Geophys. Res., 109, A03202, doi:10.1029/2003JA010281, 2004.

Gringauz, K. I.: The structure of the ionized gas envelope of the Earth from direct measurements in the USSR of local charged particle concentrations, Planet. Space Sci., 11, 281-296, 1963.

Grebowsky, J. M.: Model study of plasmapause motion, J. Geophys. Res., 75, 4329-4333, 1970.

Gustafsson, G., Boström, R., Holback, B., Holmgren, G., Lundgren, A., Stasiewicz, K., Ahlen, L., Mozer, F. S., Pankow, D., Harvey, P., Berg, P., Ulrich, R., Pedersen, A., Schmidt, R., Butler, A., Fransen, A. W. C., Klinge, D., Thomsen, M., Fälthammar, C. G., Lindqvist, P.-A., Christenson, S., Holtet, J., Lybekk, B., Sten, T. A., Tanskanen, P., Lappalainen, K., and Wygant, J.: The electric field and wave experiment for the Cluster mission, Space Sci. Rev., 79, 137-156, 1997.

Harvey, C. C.: Spatial gradient and the volumetric tensor, in: Analysis methods for Multi-Spacecraft data, edited by Paschmann, G. and Daly, P. W., ISSI Scientific Report SR-001, 307-322, 1998.

Horwitz, J. L., Comfort, R. H., and Chappell, C. R.: A statistical characterization of plasmasphere density structure and boundary 
locations, J. Geophys. Res., 95, 7937-7947, 1990.

Laakso, H. and Pedersen, A.: Ambient electron density derived from differential potential measurements, in Measurements Techniques in Space Plasmas, edited by Borovsky, J., Pfaff, P., and Young, D., AGU Monograph 102, AGU Washington D.C., 49-54, 1998.

LeDocq, M. J., Gurnett, D. A., and Anderson, R. R.: Electron number density fluctuations near the plasmapause observed by the CRRES spacecraft, J. Geophys. Res., 99, 23 661-23 671, 1994.

Lemaire, J. F.: The mechanisms of formation of the plasmapause, Ann. Geophys., 31, 175-190, 1975.

Lemaire, J. F. and Gringauz, K. I.: The Earth's Plasmasphere, with contributions from Carpenter, D. L. and Bassolo, V., Cambridge University Press, 372, 1998.

Lemaire, J. F.: The formation plasmaspheric tails, Phys. Chem. Earth (C), 25, 9-17, 2000.

Lemaire, J. F.: The formation of the light-ion-trough and peeling off the plasmasphere, J. Atmos. Terr. Phys., 63, 1285-1291, 2001.

Matsui, H., Quinn, J. M., Torbert, R. B., Jordanova, V. K., Baumjohann, W., Puhl-Quinn, P. A., and Paschmann, G.: Electric field measurements in the inner magnetosphere by Cluster EDI, J. Geophys. Res., 108, 1352, doi:10.1029/2003JA009913, 2003.

McIlwain, C. E.: Coordinates for Mapping the Distribution of Magnetically Trapped Particles, J. Geophys. Res., 66, 3681-3691, 1961.

Moldwin, M. B., Thomsen, M. F., Bame, S. J., McComas, D., and Reeves, G. D.: The fine-scale structure of the outer plasmasphere, J. Geophys. Res., 100, 8021-8030, 1995.

Moullard, O., Masson, A., Laakso, H., Parrot, M., Décréau, P. M. E., Santolik, O., and André, M.: Density modulated whistler mode emissions observed near the plasmapause, Geophys. Res. Lett., 29, (20), doi:10.1029/2002GL015101, 2002.

Paschmann, G., Melzner, F., Frenzel, R., Vaith, H., Parigger, P., Pagel, U., Bauer, O. H., Haerendel, G., Baumjohann, W., Sckopke, N., Torbert, R. B., Briggs, B., Chan, J., Lynch, K., Morey, K., Quinn, J. M., Simpson, D., Young, C., McIlwain, C. E., Fillius, W., Kerr, S. S., Maheu, R., and Whipple, E. C.: The Electron Drift Instrument for Cluster, Space Sci. Rev. 79, 233-269, 1997.

Pedersen, A.: Solar wind and magnetosphere plasma diagnostics by spacecraft electrostatic potential measurements, Ann. Geophys., 13, 118-129, 1995.

Pedersen, A., Décréau, P., Escoubet, C. P., Gustafsson, G., Laakso, H., Lindqvist, P.-A., Lybekk, B., Masson, A., Mozer, F., and Vaivads, A.: Four-point high resolution information on electron densities by the electric field experiments (EFW) on Cluster, Ann. Geophys., 19, 1483-1489, 2001.

Pierrard, V. and Lemaire, J. F.: Development of shoulders and plumes in the frame of the interchange instability mechanism for plasmapause formation, Geophys. Res. Lett., 31, L05809, doi:10.1029/2003GL018919, 2004.

Rème, H., Aoustin, C., Bosqued, J. M., Dandouras, I., Lavraud, B., Sauvaud, J. A., Barthe, A., Bouyssou, J., Camus, Th., Coeur-Joly, O., Cros, A., Cuvilo, J., Ducay, F., Garbarowitz, Y., Medale, J. L., Penou, E., Perrier, H., Romefort, D., Rouzaud, J., Vallat, C., Alcaydé, D., Jacquey, C., Mazelle, C., d'Uston, C., Möbius, E., Kistler, L. M., Crocker, K., Granoff, M., Mouikis, C., Popecki, M., Vosbury, M., Klecker, B., Hovestadt, D.,
Kucharek, H., Kuenneth, E., Paschmann, G., Scholer, M., Sckopke, N., Seidenschwang, E., Carlson, C. W., Curtis, D. W., Ingraham, C., Lin, R. P., McFadden, J. P., Parks, G. K., Phan, T., Formisano, V., Amata, E., Bavassano-Cattaneo, M. B., Baldetti, P., Bruno, R., Chionchio, G., Di Lellis, A., Marcucci, M. F., Pallocchia, G., Korth, A., Daly, P. W., Graeve, B., Rosenbauer, H., Vasyliunas, V., McCarthy, M., Wilber, M., Eliasson, L., Lundin, R., Olsen, S., Shelley, E. G., Fuselier, S., Ghielmetti, A. G., Lennartsson, W., Escoubet, C. P., Balsiger, H., Friedel, R., Cao, J.-B., Kovrazhkin, R. A., Papamastorakis, I., Pellat, R., Scudder, J., and Sonnerup, B.: First multi-spacecraft ion measurements in and near the Earth's magnetosphere with the identical Cluster ion spectrometry (CIS) experiment, Ann. Geophys., 19, 1303-1354, 2001.

Sandel, B. R., Broadfoot, A. L., Curtis, C. C., King, R. A., Stone, T. C., Hill, R. H., Chen, J., Siegmund, O. H. W., Raffanti, R., Allred, D. D., Turley, R. S., and Gallagher, D. L.: The extreme ultraviolet imager investigation for the IMAGE mission, Space Sci. Rev., 91, 197-242, 2000.

Sandel, B. R., King, R. A., Forrester, W. T., Gallagher, D. L., Broadfoot, A. L., and Curtis, C. C.: Initial Results from the IMAGE Extreme Ultraviolet Imager, Geophys. Res. Lett., 28, (8), 14391442, 2001.

Singh, N.: Refilling of a plasmaspheric flux tube: microscopic plasma processes, in Modeling Magnetospheric Plasma, edited by Moore, T. E. and Waite, J. H., AGU Geophysical Monograph 44, 87-99, Washington D.C., 1988.

Singh, N. and Horwitz, J. L.: Plasmaspheric refilling: recent observations and modelling, J. Geophys. Res., 97, 1049-1079, 1992.

Southwood, D. J., Dougherty, M. K., Balogh, A., Cowley, S. W. H., Smith, E. J., Tsurutani, B. T., Russell, C. T., Siscoe, G. L., Erode, G., Glassmeier, K.-H., Gleim, F., and Neubauer, F. M.: Magnetometer measurements from the Cassini Earth swing-by, J. Geophys. Res., 106, 30 109-30 128, 2001.

Spasojević, M., Goldstein, J., Carpenter, D. L., Inan, U. S., Sandel, B. R., Moldwin, M. B., and Reinisch, B. W.: Global response of the plasmasphere to a geomagnetic disturbance, J. Geophys Res., 108, 1340, doi:10.1029/2003JA009987, 2003.

Spiro, R. W., Harel, M., Wolf, R. A., and Reiff, P. H.: Quantitative simulation of a magnetospheric substorm, 3. Plasmaspheric electric fields and evolution of the plasmapause, J. Geophys. Res., 86, 2261-2272, 1981.

Trotignon, J. G., Décréau, P. M. E., Rauch, J. L., Randriamboarison, O., Krasnoselskikh, V., Canu, P., Alleyne, H., Yearby, K., Le Guirriec, E., Séran, H. C., Sené, F. X., Martin, Ph., Lévêque, M., and Fergeau, P.: How to determine the thermal electron density and the magnetic field strength from the CLUSTER/WHISPER observations around the Earth, Ann. Geophys., 19, 1711-1720, 2001.

Trotignon, J. G., Décréau, P. M. E., Rauch, J. L., Le Guirriec, E., Canu, P., and Darrouzet, F.: The Whisper Relaxation Sounder Onboard Cluster: A Powerful Tool for Space Plasma Diagnosis around the Earth, Cosmic Research, 41, (4), 369-372, 2003.

Tsyganenko, N. A. and Stern, D. P.: Modeling the global magnetic field of the large-scale Birkeland current systems, J. Geophys. Res., 101, 27 187-27 198, 1996. 